\title{
The influence of CYP3A5 polymorphisms on haloperidol treatment in patients with alcohol addiction
}

This article was published in the following Dove Press journal: Pharmacogenomics and Personalized Medicine

Mikhail Sergeevich

Zastrozhin ${ }^{1,2}$

Elena Anatolievna Grishina'

Kristina Anatolievna

Ryzhikova'

Valery Valerievich Smirnov 3 Ludmila Mikhailovna

Savchenko'

Evgeny Alekseevich Bryun ${ }^{1,2}$ Dmitry Alekseevich Sychev'

'Russian Medical Academy of Continuous Professional Education, Ministry of Health of the Russian Federation, ${ }^{2}$ Moscow Research and Practical Centre on Addictions, Moscow Department of Healthcare, ${ }^{3}$ National Research Center Institute of Immunology, Federal MedicalBiological Agency, Moscow, Russia

\footnotetext{
Correspondence: Mikhail Sergeevich Zastrozhin

Ministry of Health of the Russian Federation, 2/I Barrikadnaya Street, Moscow 123995, Russia

Tel +79686420092

Email rudnmed@yandex.ru
}

Background: Isoenzymes CYP2D6 and CYP3A4, the activity of which varies widely, are involved in metabolism of haloperidol and may influence its profile of efficacy and safety.

Objective: The primary aim of this study was to estimate the relationship between CYP3A5 gene polymorphism, activity of the CYP3A isoenzyme, and the risk of development of adverse drug reactions by haloperidol in patients with alcohol abuse.

Methods: Sixty-six male alcohol-addicted patients participated in the study. The safety of haloperidol was evaluated by Udvalg for Kliniske Undersogelser Side Effect Rating Scale (UKU) and Simpson-Angus Scale for extrapyramidal symptoms (SAS). The activity of CYP3A was evaluated by determining the concentrations of an endogenous substrate of this isoenzyme (cortisol) and its urinary metabolite (6-beta-hydroxycortisol, 6-B-HC). Genotyping of CYP 3 A $5 * 3$ was performed by real-time polymerase chain reaction with allele-specific hybridization.

Results: The frequency of A-allele occurrence in Russian population was very poor $(2.27 \%)$. CYP3A $5 * 3$ polymorphism had no influence on safety profile indicators of haloperidol (UKU scale: $p=0.55$, SAS scale: $p=0.64)$. In addition, there was no statistical significant difference between the values of indexes of the metabolic ratio (6-B-HC/cortisol) in groups with different genotypes of CYP3A5*3: GG $5.00(3.36 ; 6.39)$ vs AG $5.26(2.10 ; 6.78)(p=0.902)$.

Conclusion: The frequency of A-allele occurrence of CYP3A5*3 in Russian population is very poor, and it has no high influence on the safety of haloperidol treatment; therefore, there are no reasons to take this polymorphism into account in patients with alcohol addiction who receive haloperidol.

Keywords: haloperidol, CYP3A5*, CYP3A, cortisol, alcohol use disorder

\section{Background}

Haloperidol is one of the most commonly used typical antipsychotic drugs. According to the recommendations, haloperidol therapy is indicated for patients with signs of alcohol-related psychosis. ${ }^{1}$ Haloperidol treatment is often associated with development of adverse drug reactions (ADRs) (including dyskinesia, acute dystonia, arterial tension lowering, orthostatic hypotension, and arrhythmias). ${ }^{2}$

CYP3A4 catalyzes the transformation of haloperidol into 1,2,3,6-tetrahydropyridine which is metabolized further to haloperidol-pyridinium by CYP3A4 and CYP2D6. ${ }^{3}$ CYP3A4 and CYP2D6 also participate in N-dealkylation of haloperidol, ${ }^{3}$ while only CYP3A4 catalyzes the N-dealkylation of restored haloperidol. ${ }^{3}$ CYP3A4 also catalyzes the oxidation of the restored haloperidol back to haloperidolum. ${ }^{3}$ In Ghosh et al's research, it is shown that CYP3A4 is expressed not only in liver hepatocytes but also in brain neurones. ${ }^{4}$ The investigations we performed earlier, which involved 
alcohol-addicted patients, have shown the existence of statistically significant correlation between CYP2D6 gene polymorphisms, activity of this isoenzyme, and the efficacy and safety of haloperidol. ${ }^{5}$

Some studies published during 1999-2001 have reported about the influence of CYP3A4 on haloperidol metabolism and development of ADRs. ${ }^{3,6,7}$ There are also some findings regarding the absence of correlation between development of side effects during haloperidol medication and different gene polymorphisms. ${ }^{8}$ An investigation on CYP3A4*22 polymorphism shows that presence of this heterozygote does not increase the serum levels of antipsychotics (including haloperidol) which are metabolized by CYP3A4 and CYP2D6. ${ }^{9}$ The role of CYP3A5 should be investigated deeper as there is evidence that CYP3A5 catalyzes the alternative metabolic pathways which can lead to appearance of intermediate metabolites with yet unknown pharmacological properties, and it can also limit the biological availability of the drug which passes through the first metabolic pathway. Besides, the expression of CYP3A5 can inhibit CYP3A4 drug-drug interaction. ${ }^{10}$

The primary purpose of this investigation was to estimate the relationship between CYP3A5 gene polymorphism, the activity of the CYP3A isoenzyme, and the risk of development of ADRs by haloperidol in patients with alcohol addiction.

\section{Materials and methods}

The study involved 66 men with alcohol addiction, who were hospitalized in Moscow Research and Practical Centre for Addictology of the Department of Public Health. The study was approved by the local ethics committee of the Peoples' Friendship University of Russia (No. 8, February 18, 2016), and all patients provided written informed consent. During the exacerbation of the addiction, patients received haloperidol in tablet form (OOO Ozon, Zhigulevsk, Russia) in a dose of $4.34 \pm 2.38 \mathrm{mg} / \mathrm{d}$ (38 patients, once a day) or injectable form (ZAO Bryntsalov-A, Moscow, Russia) in a dose of $6.09 \pm 2.10 \mathrm{mg} / \mathrm{d}$ (32 patients, once a day). Inclusion criteria were 5-day haloperidol therapy in tablet or injection form and no concomitant mental illness in anamnesis. Exclusion criteria were the use of other psychotic drugs except haloperidol, creatinine clearance $<50 \mathrm{~mL} / \mathrm{min}$, plasma creatinine concentration $\geq 1.5 \mathrm{mg} / \mathrm{dL}(133 \mu \mathrm{mol} / \mathrm{L})$ with kidney diseases, body weight $<60$ or $>100 \mathrm{~kg}$, age of 75 years or more and contraindication to haloperidol.

The activity of CYP3A was evaluated by determining the urinary concentration of endogenous substrate of the enzyme and its metabolite - the ratio of 6-beta-hydroxycortisol
(6-B-HC) to cortisol - using high-performance liquid chromatography with mass spectrometry on an Agilent 1290 Infinity system. ${ }^{11,12}$ The higher the ratio was, the higher the activity of CYP3A was. The results are demonstrated in arbitrary units.

The safety of haloperidol was evaluated by Udvalg for Kliniske Undersogelser Side Effect Rating Scale (UKU) and Simpson-Angus Scale for extrapyramidal symptoms (SAS). Scaling of patients was performed the day before haloperidol therapy and after 5 days of therapy. The higher the difference in scores was, the more unsafe the therapy was.

Statistical analysis was done using nonparametric statistics method with the application of "Statsoft Statistica V10.0" program (Dell Statistica, Tulsa, OK, USA). When choosing a method, the normality of sample distribution was taken into account, which was evaluated with Shapiro-Wilk $W$-test. The differences were considered statistically significant at $p<0.05$. To determine the correlation between quantitative characteristics, Spearman rank correlation coefficient was calculated. Correlation coefficient $\left(r_{\mathrm{s}}\right)$ in the range of $0.3-0.7$ indicated a moderate positive, though reliable correlation between the signs, while $r_{\mathrm{s}}>0.7$ indicated a strong and reliable correlation; negative $r_{\mathrm{s}}$ value corresponded to inverse correlation.

The quantitative data are presented as mean \pm standard deviation $(\mathrm{M} \pm \sigma)$ for the normally distributed data, and median with quartiles (Me [Q1; Q3]) for nonnormally distributed data.

\section{Results}

The following results were obtained by CYP $3 \mathrm{~A} 5 * 3$ genotyping:

1. The number of patients who were the homozygous carriers of the mutant CYP3A5 gene (genotype GG) was 63.

2. The number of patients who were the heterozygous carriers of the $6986 \mathrm{~A}>\mathrm{G}$ gene polymorphism of CYP3A5 (genotype AG) was 3.

3. Patients with genotype AA were not found.

The frequency of G-allele (rs776746) was $97.73 \%$ and that of A-allele was $2.27 \%$.

The distribution of these genotypes was in agreement with Hardy-Weinberg equilibrium in European population (Fisher's exact test $p=0.85$ ).

The index of activity of CYP3A isoenzymes, which was measured using the ratio of concentration of $6-\mathrm{B}-\mathrm{HC}$ to concentration of cortisol, was 4.99 [3.34; 6.39].

Mann-Whitney $U$-test showed that there was no statistically significant difference in indicators of safety profile 
of haloperidol treatment (measured using the difference in scores on UKU and SAS scales) in patients with different genotypes of CYP3A5 6986G>A (Table 1).

The values of the metabolic ratio $(6-\mathrm{B}-\mathrm{HC} /$ cortisol) in groups with different genotypes of CYP3A $5 * 3$ were compared using Mann-Whitney $U$-test, which showed no statistically significant difference between the values of index: 5.00 [3.36; 6.39] vs $5.26[2.10 ; 6.78](p=0.902)$ (Figure 1).

Comparison of the results of genotyping obtained from alcohol-dependent patients of Russian nationality with data obtained earlier from other ethnic groups showed the absence of statistically significant difference in the distribution of genotypes in Tatars and Russians, but presence of statistically significant difference in distribution in Bashkirs. ${ }^{13}$ In Mustafina et al's research, A-allele gene CYPA5*3 was identified in Tatar population with a frequency of $94.3 \%$ ( $\mathrm{OR}=2.60$ [95\% CI, 0.80; 8.42], $p=0.10)$, Bashkir population with a frequency of $91.5 \%(\mathrm{OR}=4.03$ [95\% CI, 1.23; 13.140], $p=0.01$ ), and Russian population with a frequency of $94.6 \%$ $(\mathrm{OR}=2.46$ [95\% CI, 0.75; 8.02), $p=0.12)$ (Table 2).

Table I The results of Mann-Whitney U-test evaluating differences in scores on UKU and SAS scales in patients with different genotypes of CYP3A5 6986A>G

\begin{tabular}{llll}
\hline Scale & $\begin{array}{l}\text { GG-genotype } \\
\text { patients }\end{array}$ & $\begin{array}{l}\text { AG-genotype } \\
\text { patients }\end{array}$ & $\boldsymbol{p}$ \\
\hline UKU & $-8.16 \pm 1.86$ & $-7.93 \pm 1.34$ & 0.558621 \\
SAS & $-4.16 \pm 0.69$ & $-4.13 \pm 0.5$ & 0.644256 \\
\hline
\end{tabular}

Abbreviations: SAS, Simpson-Angus Scale for extrapyramidal symptoms; UKU, Udvalg for Kliniske Undersogelser Side Effect Rating Scale.
The Spearman correlation analysis demonstrated a statistically nonsignificant very poor positive correlation between the concentrations of 6-B-HC, cortisol, their ratio, and the difference in scores on the UKU and SAS scales (the safety of therapy) in patients who received haloperidol in tablet form (Table 3 ), but a statistically significant moderate positive correlation between the concentrations of 6-B-HC, cortisol, their ratio, and the difference in scores on the UKU and SAS scales (the safety of therapy) in patients who received haloperidol in injectable form (Table 4).

Linear regression analysis allowed us to construct a model of correlation between the activity of CYP3A and difference in scores on the UKU scale as a primary scale for the evaluation of safety profile in psychiatric patients receiving haloperidol in injectable form (Figure 2).

Coefficients of linear regression $y=a+b \cdot x$ (where $x$ is the index of the activity of CYP2D6, $y$ is the difference in points on a scale, $a$ and $b$ are the coefficients of the equation), which demonstrate the correlation between the activity of CYP3A and difference in scores on UKU and SAS scales, are presented in Table 5.

\section{Discussion}

The results of the study demonstrated that the frequency of genotypes AA and AG of allelic variant CYP3A5*3 in Russian population is extremely poor and it probably could influence the results of statistical data. It is shown that CYP3A5 6986A $>$ G polymorphism has no statistically significant influence on the safety of haloperidol treatment in patients

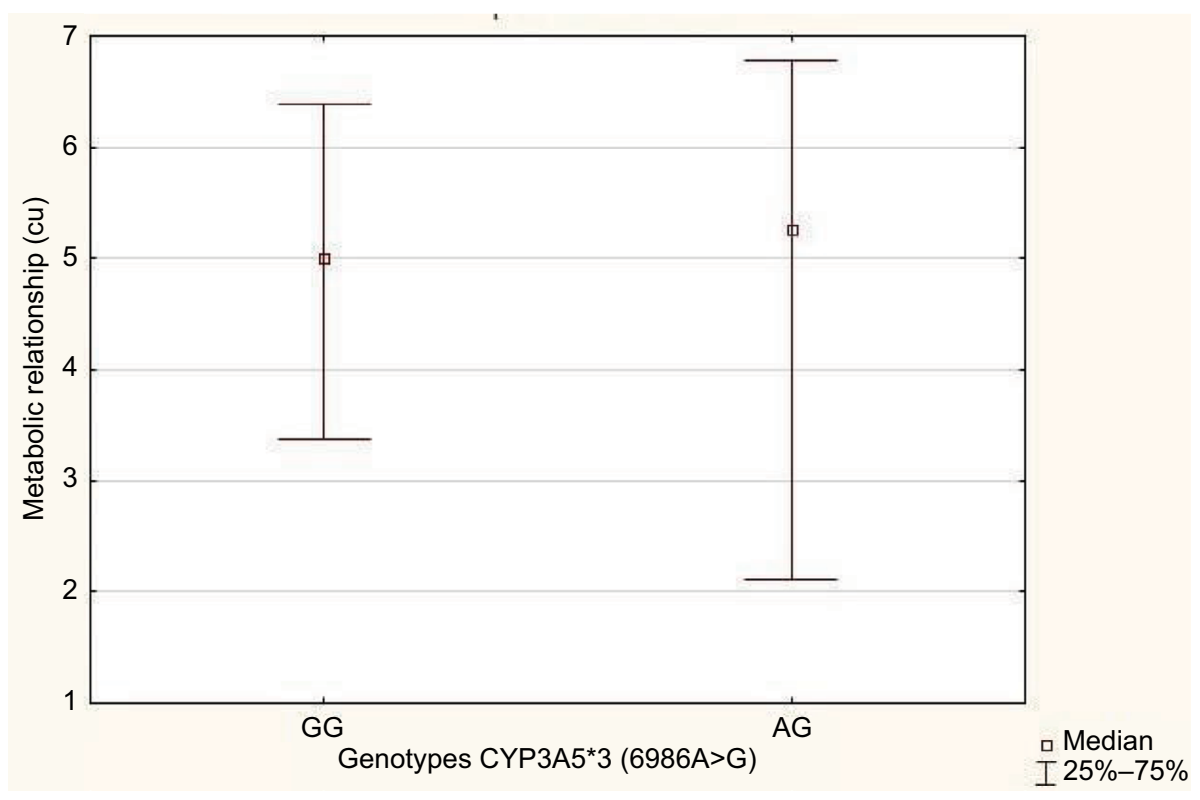

Figure I Metabolic 6-B-HC/cortisol ratio in patients with genotypes of GG and AG on a polymorphic marker 6986A>G of CYP3A5 gene. Abbreviations: 6-B-HC, 6-beta-hydroxycortisol; cu, conditional units. 
Table 2 Comparison of genotypes and allele distribution of CYPA5 gene according to polymorphic marker 6986A $>$ G in current study population and in different ethnic groups in earlier studies

\begin{tabular}{|c|c|c|c|c|c|c|c|c|c|}
\hline \multirow[t]{2}{*}{ Population } & \multirow[t]{2}{*}{$\mathbf{n}$} & \multirow{2}{*}{$\begin{array}{l}\text { GG } \\
\text { genotype } \\
\text { (\%) }\end{array}$} & \multirow{2}{*}{$\begin{array}{l}\text { AG } \\
\text { genotype } \\
\text { (\%) }\end{array}$} & \multirow{2}{*}{$\begin{array}{l}\text { AA } \\
\text { genotype } \\
(\%)\end{array}$} & \multirow[t]{2}{*}{ G allele (\%) } & \multirow[t]{2}{*}{$\begin{array}{l}\text { A allele } \\
(\%)\end{array}$} & \multicolumn{3}{|c|}{$\begin{array}{l}\text { Comparison with the results } \\
\text { of our research }\end{array}$} \\
\hline & & & & & & & $\overline{\mathbf{C h i}^{2}}$ & $p$ & OR $(95 \%, \mathrm{CI})$ \\
\hline Russians & 66 & $63(95.45)$ & $3(4.76)$ & $0(0)$ & $129(97.73)$ & $3(2.27)$ & - & - & - \\
\hline Russians $^{13}$ & 443 & $204(46.05)$ & $25(12.25)$ & $0(0)$ & $838(94.6)$ & $48(5.4)$ & 2.39 & 0.12 & $2.46(0.75 ; 8.02)$ \\
\hline Tatars $^{13}$ & 517 & $124(23.98)$ & $16(12.9)$ & $0(0)$ & $975(94.3)$ & $59(5.7)$ & 2.74 & 0.10 & $2.60(0.80 ; 8.42)$ \\
\hline Bashkirs $^{13}$ & 280 & $99(35.36)$ & $2 \mathrm{I}(2 \mathrm{I} .2 \mathrm{I})$ & I (4.76) & $512(9 \mid .5)$ & $48(8.5)$ & 6.21 & 0.01 & $4.03(1.23 ; 13.14)$ \\
\hline
\end{tabular}

Table 3 The results of correlation analysis between the safety of haloperidol in tablet form and CYP3A activity in patients with alcohol abuse

\begin{tabular}{lllllll}
\hline Scale & $\boldsymbol{r}_{\mathrm{s}}$ & & & & & \\
\cline { 2 - 7 } & Concentration of cortisol & $\boldsymbol{p}$ & Concentration of 6-B-HC & $\boldsymbol{p}$ & Ratio of 6-B-HC/cortisol & $\boldsymbol{p}$ \\
\hline UKU & 0.068 & $>0.05$ & 0.056 & $>0.05$ & -0.011 & $>0.05$ \\
SAS & 0.092 & $>0.05$ & 0.073 & $>0.05$ & -0.017 & $>0.05$ \\
\hline
\end{tabular}

Abbreviations: 6-B-HC, 6-beta-hydroxycortisol; SAS, Simpson-Angus Scale for extrapyramidal symptoms; UKU, Udvalg for Kliniske Undersogelser Side Effect Rating Scale.

Table 4 The results of correlation analysis between the safety of haloperidol in injectable form and CYP3A activity in patients with alcohol abuse

\begin{tabular}{lllllll}
\hline Scale & $\boldsymbol{r}_{\mathrm{s}}$ & & & & \\
& Concentration of cortisol & $\boldsymbol{p}$ & Concentration of 6-B-HC & $\boldsymbol{p}$ & Ratio of 6-B-HC/cortisol & $\boldsymbol{P}$ \\
\hline UKU & -0.227 & $>0.05$ & 0.091 & $>0.05$ & 0.327 & $<0.05$ \\
SAS & -0.171 & $>0.05$ & 0.184 & $>0.05$ & 0.423 & $<0.05$ \\
\hline
\end{tabular}

Abbreviations: 6-B-HC, 6-beta-hydroxycortisol; SAS, Simpson-Angus Scale for extrapyramidal symptoms; UKU, Udvalg for Kliniske Undersogelser Side Effect Rating Scale.

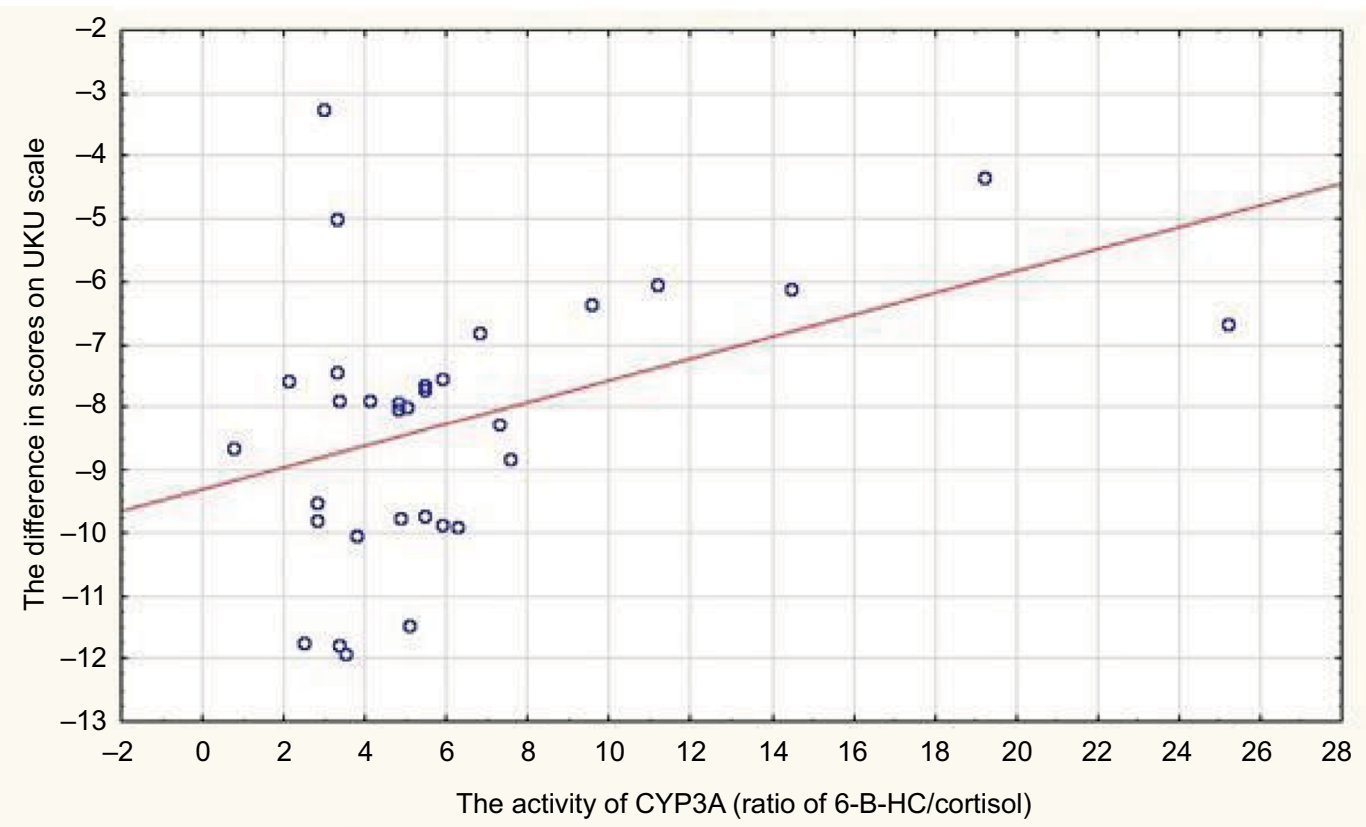

Figure 2 Relationship between the activity of CYP3A and difference in scores on UKU scale in patients receiving haloperidol in injection form. Abbreviations: 6-B-HC, 6-beta-hydroxycortisol; UKU, Udvalg for Kliniske Undersogelser Side Effect Rating Scale. 
Table 5 Coefficients of linear regression $y=a+b \cdot x$, demonstrating correlation between activity of CYP3A and difference in scores on UKU and SAS scales

\begin{tabular}{lllll}
\hline Scale & $\boldsymbol{a}$ & $\boldsymbol{p}$ & $\boldsymbol{b}$ & $\boldsymbol{p}$ \\
\hline UKU & -9.31 & $<0.01$ & 0.21 & $<0.01$ \\
SAS & -4.71 & $<0.05$ & 0.11 & $<0.05$ \\
\hline
\end{tabular}

Abbreviations: SAS, Simpson-Angus Scale for extrapyramidal symptoms; UKU, Udvalg for Kliniske Undersogelser Side Effect Rating Scale.

with alcohol addiction. In addition, there was no statistically significant effect of CYP3A5 6986A $>G$ on the index of the activity of CYP3A, but there were statistically significant moderate correlations between the activity of CYP3A and the safety of haloperidol treatment. Also, we should note that, although CYP3A5 and CYP3A4 share high homology and similar substrate specificity, their contributions to the metabolism of drugs are often different, so the activity of CYP3A4 or CYP3A5 should be detected by the isoform-specific probe substrates. Therefore, we suppose that the effect of CYP 3 A $5 * 3$ polymorphism on CYP3A activity is very poor, but the safety profile of haloperidol is dependent on CYP3A activity because haloperidol may be a substrate of CYP3A4. We did not investigate the influence of polymorphism of CYP3A4 on the safety of haloperidol treatment, but we assume that research on this area may provide interesting results.

\section{Conclusion}

The frequency of A-allele of CYP3A5*3 in Russian population is very poor, and there is no high influence on the safety of haloperidol treatment; therefore, there is no reason to take this polymorphism into account in patients with alcohol addiction who receive haloperidol.

\section{Acknowledgment}

This work was supported by the project titled "Fundamental research and exploratory research in priority areas of research" (No. 16-15-00227) of the Russian Science Foundation.

\section{Disclosure}

The authors report no conflicts of interest in this work.

\section{References}

1. Stewart S, Swain S; NICE; Royal College of Physicians, London. Assessment and management of alcohol dependence and withdrawal in the acute hospital: concise guidance. Clin Med (Lond). 2012; 12(3):266-271.

2. Ivanec NN. Drug Addiction: National Leadership. Moscow: GEOTAR Media; 2008.

3. Fang J, McKay G, Song J, Remillrd A, Li X, Midha K. In vitro characterization of the metabolism of haloperidol using recombinant cytochrome p450 enzymes and human liver microsomes. Drug Metab Dispos. 2001;29(12):1638-1643.

4. Ghosh C, Marchi N, Desai NK, et al. Cellular localization and functional significance of CYP3A4 in the human epileptic brain. Epilepsia. 2011;52(3):562-571.

5. Sychev DA, Zastrozhin MS, Smirnov VV, Grishina EA, Savchenko LM, Bryun EA. The correlation between CYP2D6 isoenzyme activity and haloperidol efficacy and safety profile in patients with alcohol addiction during the exacerbation of the addiction. Pharmacogenomics Pers Med. 2016;9:89-95.

6. Watanabe M, Tomonori T, Asoh M, et al. Role of CYP3A in haloperidol $\mathrm{N}$-dealkylation and pharmacokinetics in rats. Fundam Clin Pharmacol. 1999;13(3):337-342.

7. Pan L, Belpaire FM. In vitro study on the involvement of CYP1A2, CYP2D6 and CYP3A4 in the metabolism of haloperidol and reduced haloperidol. Eur J Clin Pharmacol. 1999;55(8):599-604.

8. Drago A, Giegling I, Schäfer M, et al. No association of a set of candidate genes on haloperidol side effects. PLoS One. 2012;7(10): e44853.

9. van der Weide $\mathrm{K}$, van der Weide J. The influence of the CYP3A4*22 polymorphism and CYP2D6 polymorphisms on serum concentrations of aripiprazole, haloperidol, pimozide, and risperidone in psychiatric patients. J Clin Psychopharmacol. 2015;35(3):228-236.

10. Ragia G, Dahl ML, Manolopoulos VG. Influence of CYP3A5 polymorphism on the pharmacokinetics of psychiatric drugs. Curr Drug Metab. 2016;17(3):227-236.

11. Emelyanov MI, Smirnov VV, Litvin AA, Kolyvanov GB, Blynskaya EV, Kondakov SE. Assay of cortisol and its metabolite in the rat urine by HPLC-MS method. Moscow Univ Chem Bull. 2013;68(1): $51-53$.

12. Luo X, Li XM, Hu ZY, Cheng ZN. Evaluation of CYP3A activity in humans using three different parameters based on endogenous cortisol metabolism. Acta Pharmacol Sin. 2009;30(9):1323-1329.

13. Mustafina OE, Tuktarova IA, Karimov DD, Somova RS, Nasibullin TR. [CYP2D6, CYP3A5, and CYP3A4 gene polymorphism in Russian, Tatar, and Bashkir populations]. Genetika. 2015;51(1): 109-119. Russian [with English abstract].
Pharmacogenomics and Personalized Medicine

\section{Publish your work in this journal}

Pharmacogenomics and Personalized Medicine is an international, peerreviewed, open access journal characterizing the influence of genotype on pharmacology leading to the development of personalized treatment programs and individualized drug selection for improved safety, efficacy and sustainability. This journal is indexed on the American Chemical

\section{Dovepress}

Society's Chemical Abstracts Service (CAS). The manuscript management system is completely online and includes a very quick and fair peer-review system, which is all easy to use. Visit http://www.dovepress. com/testimonials.php to read real quotes from published authors. 